\title{
An Audit of Mandibular Third Molar Surgery
}

\section{B. D. O. Saheeb and O. N. Obuekwe}

Department of Oral and Maxillofacial Surgery, University of Benin Teaching Hospital, Benin City, Nigeria.

Reprint Requests to: Dr. B. D. O. Saheeb, P. O. Box 2799, Benin City, 300-001, Edo State, Nigeria. E-mail: dauda2000@yahoo.com

\section{ABSTRACT}

Background: The objective of this audit was to identify areas where there could be improvement in patient management as well as evaluating our methods of treatment and effective utilisation of resources.

Methods: A retrospective study of mandibular third surgery at the University of Benin 'Teaching Hospital, Benin City in one year.

Results: A total of 149 impacted mandibular third molars were surgically removed from 133 patients. There were $70(47 \%)$ males and $79(53 \%)$ females with an age range of $18-78$ years. The commonest type of impaction was mesioangular $95(63.8 \%)$. The commonest indication for surgery was pericoronitis $48(32.2 \%)$. One hundred and twenty five (94\%) of patients had local anaesthesia while $8(6 \%)$ had local anaesthesia/intravenous. Four $(2.7 \%)$ patients had paraesthesia of the lower lip as a result of inferior alveolar nerve damage while one $(0.7 \%$ ) had lingual nerve paraesthesia. No proper record keeping of procedures was observed in all the cases analysed.

Conclusion: This study has identified poor record keeping and non-adherence to standard protocol by residents in patient management.

KEYWORDS: Audit, Mandibular, Third Molar, Surgery

\section{Introduction}

Nowadays, clinical audit is becoming an essential tool for examining the quality of health care delivery. Simpson and Shaw have identified three important objectives of a medical audit 1) to improve the quality of patients care 2) to increase the quality of training and education of clinical staff and 3) to permit an effective use of resources. 1 Although oral and maxillofacial surgery is expanding its frontiers of practice, third molar surgery still remains the most commonly performed surgery 
by the specialist surgeon. 2 Of the 284 surgical procedures carried out at our centre in 1999, 52.5\% were impacted wisdom teeth. Quite often, the surgical removal of these teeth is attended by complications, which are distressing to the patients, and have been variously highlighted in previous reports. 3.0 Of all the complications, sensory disturbance appears to be more prolonged and distressing to the patient and frequently results in litigation in some developed countries.

The authors undertook an audit of the technique and morbidity associated with the removal of impacted third molars in our centre. This was necessary to evaluate our methods of treatment, identify areas where there could be improvement in patient management as well as ascertain the effective use of resources.

\section{Materials and Methods}

In 1999, an audit of all surgically extracted mandibular third molars was undertaken at the Oral and Maxillofacial Surgery Clinic of the University of Benin Teaching Hospital, Benin, Nigeria. The case notes were obtained from the Medical Records Department and reviewed. The use of pariapical radiographs to assess the relationship of roots and crowns to adjacent structures was noted. Furthermore, we noted the use of additional assessment based on WHARFE. 7 The WHARFE assessment takes into account the angulation of lower third molar(s) using Winter's classification (W), the height $(\mathrm{H})$ of the mandible, angulation (A) of second molar, the shape and development of root (R), the size of the follicular sac $(F)$ and the path of exit (E) of the tooth.

\section{Surgical Procedure}

A11 surgical procedures were carried out on a dental chair either under a local anaesthetic (L.A) agent or L.A/intravenous sedation with standard surgical protocols observed. The instruments used were the same in every case. A buccal mucoperiosteal flap extending to the external oblique ridge was raised in all cases with a vertical buccal relieving incision. Care was taken to avoid raising a lingual flap or using a retractor on the lingual tissues. Osteotomy of bone was performed using a round bur and where necessary tooth sectioning was carried out a fissure bur on a straight hand piece with constant irrigation using normal saline solution. A 3/0 black silk suture was used for closure of the wound and was removed after five days of surgery. All patients received oral antibiotics and non-steroidal antiinflammatory analgesics (NSAIA) for a minimum of five days. Post operative specific instructions on oral care were given to all the patients. They were also advised to report immediately to the hospital or the nearest clinic to patient if there was any untoward consequence of surgery. 


\section{Results}

A total of 149 mandibular impacted third molars were surgically extracted from 133 consecutive patients who attended the Oral and Maxillofacial Surgery Clinic in 1999. There were $70(47.0 \%)$ males and 79 $(53.0 \%)$ females with an age range of $18-74$ years (28 years). Of the 149 impacted third molars, 79 (53.0\%) were on the left side of the jaw, while $70(47.0 \%)$ were on the right side. Sixteen $(12.0 \%)$ patients had bilateral impaction, while 117 $(88.0 \%)$ had unilateral impaction. No patient with bilateral impaction had the two teeth removed at the same visit. There were more impartions $(1071.8 \%)$ within the 21 - 30 years age range.

The commonest type of impaction was the mesioangular variety 95 $(63.8 \%)$ and this was the most frequent among the females 47 $(31.5 \%)$ aged range $21-30$ years. This type of angulation was also the commonest among males 3 (20.8\%) aged 21- 30 years (Table 1). The state of eruption of the tecth before surgery was not recorded.

The commonest recorded indications for surgery was urvilateral pericoronitis 48 (32.2\%), caries $44(29.6 \%)$ and apical periodontitis $44(29.6 \%$ ) (Table2) The commonest post operative complaint was pain, $8(5.4 \%)$ mosily from females $5(3.4 \%)$. Surgical removal of mesioangular and vertical impactions $3(2.0 \%)$ respectively were more frequently involved in post-operative pain than any other type of impaction. Root fracture was commonly associated with mesioangular impaction and this was encountered in $4(2.7 \%)$ patients.

One hundred and twenty five patients $(94.0 \%)$ were administered local anacsthetic agent (lignocaine with 1:80,000 adrenaline). Eight. patients $(6.0 \%)$ bid L.A with intravenous sedation. One hundred and forty $(94.0 \%)$ thind molars were extracted using burs and elevators while $9(60 \%)$ were extracted using chisel.

Acute alvenlar osteitis (diry socket) was recorded ir $3(2.6 \%)$ patients of age range $22-27$ years of these, $2(1.3 \%)$ casess were arsociated with horizontal impaction, while the other was assorialed with a distoangular impaction. Paraesthesia of the lower lip associated with damaze to the incror alyeolar nerve was observed in $4(2 . \% \%)$ patients and was assuciatcd thith horizontal impaction. There was ooe case $(0.7 \%)$ of lingual nerve paraesthesia, which was associated with a horizontal impaction in a female patient. All cases of post operative sensory disturbance recovered sensation within 3-\$ woeks and no lingering paracesthesia or dysaethesia was recorded. There was however, no pre-operative waming to patients of possible sensory deficit following surgery necorded.

Oral antibulics and analgesics were ronumely prescribed for the patients after sugery. No general anaestheshid, steroid and mouthwashes were used apart from hot salt mouthwash. The frequently prescribed analgesios were diclofenac $68(45.6 \%)$, paraceramol $52(34.0 \%)$ 


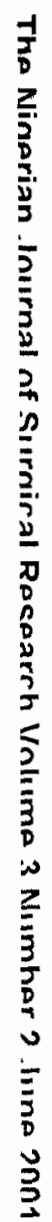

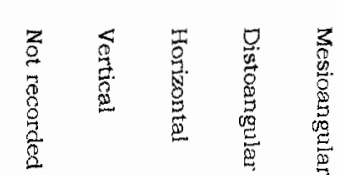

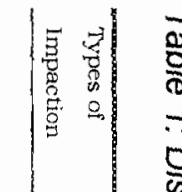

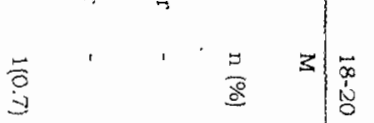

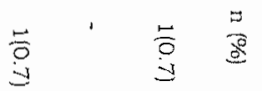

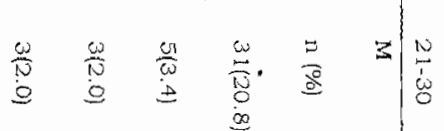

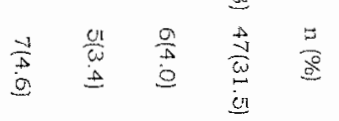

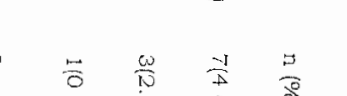

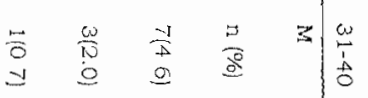

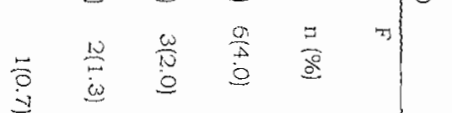

$\frac{O}{\frac{O}{5}}$

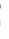

$\geq 1$

$\stackrel{5}{9}$

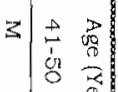

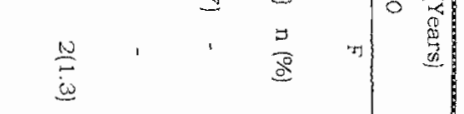

$\sum_{\substack{0 \\ 0}}^{0}$

$\omega$

3

$\frac{5}{5}$

$\stackrel{0}{2}$

क्ष

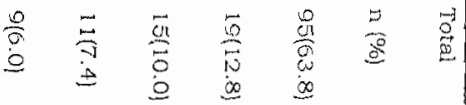

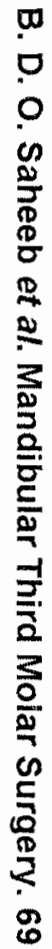




\section{B. D. O. Saheeb et al. Mandibular Third Molar Surgery. 70}

Piroxicam 27(18.1\%), Ibuprofen, $2(1.3 \%)$ and pentazocine intramuscular injection in $3(2.0 \%)$ patients. Similarly, amoxycillin was the commonest single antibiotic prescribed $24(16.1 \%)$ and it was also the commonest prescribed antibiotic combined with metronidazole $58(38.9 \%)$ (Table 3). In all the cases, there were no prophylactic antibiotics given to any of the patients prior to surgery. Follow up review was arranged for all the patients until the sockets healed and where nerve damage had ccurred, follow up was as long as three months.
Table 2: Reasons for Surgery

\begin{tabular}{ll} 
Indications for Surgery & $\begin{array}{l}\text { No. } \\
(\%)\end{array}$ \\
\hline Pericoronitis & $48(32.2)$ \\
Caries & $44(29.5)$ \\
Apical Periodontitis & $44(29.5)$ \\
Pulpitis & $7(4.7)$ \\
Fractured teeth & $4(2.7)$ \\
Alveolar abscess & $2(1.4)$
\end{tabular}

Table 3: Antibiotics Commonly Prescribed

$\begin{array}{ll}\text { Antibiotics } & \begin{array}{l}\text { No. } \\ \text { Amoxycillin }\end{array} \\ \begin{array}{l}\text { Amoxycillin/metro- } \\ \text { nidazole }\end{array} & 58(38.9) \\ \text { Ampiclox } & 12(8.1) \\ \begin{array}{l}\text { Ampiclox/metro- } \\ \text { nidazole }\end{array} & 22(14.8) \\ \text { Ampicillin } & 4(2.7) \\ \begin{array}{l}\text { Ampicillin/metro- } \\ \text { nidazole }\end{array} & 10(6.7) \\ \text { Metronidazole } & 9(6.0) \\ \text { Erythromycin } & 9(6.0) \\ \text { Doxycline } & 1(0.7) \\ & \end{array}$




\section{Discussion}

Most of the surgical extractions of impacted third molars carried out in our centre are done under local anaesthesia. This is because of patients' preference and the cost of using general anaesthesia for such a minor procedure. For instance, the cost of surgical extraction under local anaesthesia in our environment is about 20 Dollars whereas the same operation under general anaesthesia would attract more than twice this amount. Therefore, we found it more expedient and cost effective to use L.A for our patients especially in Nigeria where the average income is about 75 Dollars a month. However, there are some patients whose levels of anxiety are so high that they will consider treatment only under general anaesthesia8. Such patients who were obviously nervous about operation were given the option of a general anaesthesia or local anaesthesia with intravenous sedation with the problems associated with either procedure fully explained to the patients. Less than 10 percent of patients preferred the use of L.A/intravenous sedation, which is consistent with findings elsewhere. 0. 7.0 Alihough no patient in this audit was administered G.A before extraction, recent reports confirmed the regular use of G.A for lower third molar surgery in the United Kingdom. ${ }^{10.11}$ Previous work has identified the reason for this, as a reflection of the fact that dental practitioners think third molar disease is more common than it really is. 12 Nonetheless, some centres in the U.K who had adopted this practice are reducing the number of third molars removal under G.A 13 because of the high incidence of nerve damage.

The indications for surgery and post-operative complication are consistent with previous reports. It was observed that although periapical radiographs were taken to assess the teeth to be extracted, there were no records in all the case notes of the anatomical relationship of the tooth to the adjacent structures and the state of tooth eruption before surgery. Furthermore, the use of WHARFE in assessing surgical difficulty was not strictly adhered to in all procedures.

The incidence of inferior alveolar nerve damage was $2.7 \%$ and was frequently associated with horizontally impacted teeth. Although it is possible to predict inferior alveolar nerve damage by radiographic assessment, i1 damage to this nerve still occurred and was also found more often with horizontally impacted teeth in other studies. 0.15 The lingual paraesthesia observed in this audit was associated with a horizontal impaction and this was a similar finding in a West of Scotland study. This apparent low incidence of lingual nerve damage could be attributed to our method 


\section{B. D. O. Saheeb et al. Mandibular Third Miolar Surgery. 72}

of raising the buccal mucoperiosteal flap without raising the lingual flap-a method that has been claimed to present no risk to the lingual nerve ${ }^{16}$ and used by some clinicians 17 to achieve a low incidence of lingual nerve paraesthesia.

The present audit indicates that antibiotics and analgesics were routinely prescribed postoperatively to most patients after third molar surgery regardless of their health status. 'This practice agrees with earlice reports, is but while the commonest antibiotics found to be administered in this audit was amoxycilliu, majonty of the clinicians in the previous reports is favours benzyl pexicillin and phenoxymethyl penicillin. Where a combination of antibiotics was indicated, metronidazole was irequeitly combined with amoxycillin. Inspite of this, there was a post. operative acite alveolar ostcitis of $2 \%$, which was higher than in some previous works where a figure of 0.6 percent was report. 3 There are theoretical limitations of comparing such reports because it would seem that occurence of $0.6 \%$ in about 1000 mandibular third molar extraction is is significantly higher than that found in the present audit. There are other documented reasons for the occurrence of dry socket, however, Macgregor found the occurrence of this infection predominately in the age range of 30.34 years. 19 Although our sample is smaller, the incidenoe was found in younger age group of $22-27$ years.

In conclusion, areas of weakness in patient management have been identified. In particular, we have been able to identify poor record keeping of procedures, pre and postoperative fondings and insulficient clinical details in all the cases studied. We did not know to what extent these lapses affected the health of the patients neveribeinss, corrective measures have since been instituted and clost stupervision by the senion menters of statl ate yelding good results. The findinge in this audit worulal therefore moduce some base lint information on the adberence of frabed rowdenis to some stanchard protocol.

\section{Acknowitedgenenth}

Wo ar grateful to all the residens in the Department of Oral aud Maxillofacial Surgery who helped in retrieving the case inotest.

\section{Rerencrocess}

1. Simpson NB, Shaw CD. Medical andi for dermat. ologist atod dermatology deparment in Champion RH, Rye Re (eds). Recent advances in dernatology. Churchill livingstone, lidinburgh, 1992: $167-183$. 
2. Mercier P, Precious D. Risk and benefits of removal of impacted third molars. Int $\mathrm{J}$ Oral Maxillofacial Surg 1992; 21:17-21.

3. Chiapasco M, Decico L, Marrone G. Side effects and complications associated with third molar surgery. Oral Surg Oral Med Oral Pathol 1993; 76:412-420.

4. Blackburn CW, Bramley PA. Lingual nerve damage associated with the removal of lower third molars. Br Dent J 1989; 167:103-107.

5. Williams M. Post-operative nerve damage and the removal of mandibular third molars: a matter of common consent. $\mathrm{Br}$ J Oral Maxillofac Surg 1996; 34:366-368.

6. Carmichael FA, McGowan DA. Incidence of nerve damage following third molar removal: A West of Scotland Oral Surgery Research Group study. $\mathrm{Br} J$ Oral Maxillofac Surg 1992; 30:78-82.

7. Macgregor AJ. The impacted lower wisdom tooth. Oxford: Oxford Medical Publications 1985:52.

8. Van sickles JE, Tiner BD. Cost of a genioplasty under intravenous sedation in a private office versus general anaesthesia in an out patient surgical center. J Oral Maxillofac Surg 1994; 50: 687-690.

9. Lopess V, Mumenya R, Feinmann C. Third molar surgery: an audit of indications for surgery, postoperative complaints and patients satisfaction. $\mathrm{Br} J$ Oral Maxillofac Surg 1995; 33:33-35.

10. Worral, SF, Riden K, Haskell R. Carrigan AM. UK third molar project: the initial report. $\mathrm{Br} \mathrm{J}$ Oral Maxillofac Surg 1998; 36: $14-18$.

11. Edwards DJ, Brickley MR, Horton J, Edward MJ, Shepherd JP. Choice of anaesthesia and health care facility for third molar surgery. $\mathrm{Br} \mathrm{J}$ Oral Maxillofac Surg 1998; 36:333-340.

12. Kauffman E, Weinstein $P$, Milgrom P. Difficulties in achieving local anaesthesia. J Am Dent Assoc 1984; 108: 205-209.

13. Brann CR, Brickley MR, Shepherd JP. Factors influencing damage during third molar surgery. Br Dent $J$ 1999; 186: 514-516.

14. Rood JP, Shehab BAAN. The radiological prediction of inferior alveolar nerve injury during third molar surgery. $\mathrm{Br}$ J Oral Maxillofac Surg 1990; 28:20-25.

15. Kipp DP, Goldstein BH, Weiss WW. Dysaethesia after mandibular third molar surgery; a retrospective study and an analysis of 1377 surgical procedures. J. Am. Dent. Assoc. 1980; 100:185192.

16. McGurk M, Haskell R. Editorial. Wisdom tooth removal and lingual nerve 
damage. Br J Oral Maxillofac Surg 1999; 37:253-254.

17. Robinson PP, Smith KG. Lingual nerve damage during lower third molar removal: a comparison of two surgical methods Br Dent J 1996; 180:456-461.
18. Falconer D'T, Roberts EE. Report of an audit into third molar exodontia. $\mathrm{Br} \mathrm{J}$ Oral Maxillofac surg 1992; 30: 183-185.

19. Macgregor AJ. Aetiology of dry socket. Br J Oral Surg 1968; 6:49-58. 